\title{
Limited Sensitivity of Hippocampal Synaptic Function or Network Oscillations to Unmodulated Kilohertz Electric Fields
}

\author{
Zeinab Esmaeilpour, ${ }^{1}$ Mark Jackson, ${ }^{1}$ Greg Kronberg, ${ }^{1}$ Tianhe Zhang, ${ }^{2}$ Rosana Esteller, ${ }^{2}$ Brad Hershey, ${ }^{2}$ \\ and Marom Bikson ${ }^{1}$
}

https://doi.org/10.1523/ENEURO.0368-20.2020

${ }^{1}$ Neural Engineering Laboratory, Department of Biomedical Engineering, The City College of the City University of New York, City College Center for Discovery and Innovation, New York, 10031 NY and ${ }^{2}$ Boston Scientific Neuromodulation Research and Advanced Concepts, 25155 Rye Canyon Loop, Valencia, CA 91355

\begin{abstract}
Understanding the cellular mechanisms of kilohertz $(\mathrm{kHz})$ electrical stimulation is of broad interest in neuromodulation including forms of transcranial electrical stimulation, interferential stimulation, and high-rate spinal cord stimulation (SCS). Yet, the well-established low-pass filtering by neuronal membranes suggests minimal neuronal polarization in respond to charge-balanced $\mathrm{kHz}$ stimulation. The hippocampal brain slice model is among the most studied systems in neuroscience and exhaustively characterized in screening the effects of electrical stimulation. High-frequency electric fields of varied amplitudes $(1-150 \mathrm{~V} / \mathrm{m}$ ), waveforms (sinusoidal, symmetrical pule, asymmetrical pulse) and frequencies (1 and10 kHz) were tested. Changes in single or paired-pulse field EPSPs (fEPSP) in CA1 were measured in response to radial-directed and tangential-directed electric fields, with brief $(30 \mathrm{~s})$ or long $(30 \mathrm{~min})$ application times. The effects of $\mathrm{kHz}$ stimulation on ongoing endogenous network activity were tested in carbachol-induced $\gamma$ oscillation of CA3a and CA3c. Across 23 conditions evaluated, no significant changes in fEPSP were resolved, while responses were detected for withinslice control direct current (DC) fields; $1-\mathrm{kHz}$ sinusoidal and pulse stimulation $(\geq 60 \mathrm{~V} / \mathrm{m})$, but not $10 \mathrm{kHz}$, induced changes in oscillating neuronal network. We thus report no responses to low-amplitude $1-\mathrm{kHz}$ or any $10-\mathrm{kHz}$ fields, suggesting that any brain sensitivity to these fields is via yet to be-determined mechanism(s) of action which were not identified in our experimental preparation.
\end{abstract}

Key words: brain stimulation; $\gamma$ oscillation; high-frequency stimulation; kilohertz electrical stimulation; neuronal excitability

\section{Significance Statement}

There a large mismatch between enthusiasm for clinical treatments using kilohertz $(\mathrm{kHz})$ frequency electrical stimulation and the understanding of $\mathrm{kHz}$ mechanisms of action. Indeed, the well-established low-pass properties of cell membranes should attenuate any response to $\mathrm{kHz}$ stimulation. This study presents the largest and broadest characterization of the cellular effects of $\mathrm{kHz}$ stimulation using the most established animal model to detect CNS sensitivity to electric fields: our work systematically evaluated sensitivity of hippocampal synaptic function and oscillatory network activity in response to $\mathrm{kHz}$. Only at low $\mathrm{kHz}$ (1 but not $10 \mathrm{kHz}$ ) with high intensity and during oscillations, responses were detected. This systematic and largely negative experimental series suggest $\mathrm{kHz}$ neuromodulation operates via yet to be determined mechanisms.

Received August 25, 2020; accepted November 5, 2020; First published December 8, 2020.
The City University of New York holds patents on brain stimulation with M.B. as inventor. M.B. has equity in Soterix Medical Inc. M.B. also consults, received grants, assigned inventions, and/or serves on the Science Advisory Board of Boston Scientific, GlaxoSmithKline, Mecta, and Halo Neuroscience. All other authors declare no competing financial interests. 


\section{Introduction}

Electric fields at low frequencies $(<100 \mathrm{~Hz})$ are highly effective in changing firing rate and timing of neuronal population (Mclntyre et al., 2004; Fröhlich and McCormick, 2010), including at very low $(\sim 1 \mathrm{~V} / \mathrm{m})$ intensities (Reato et al., 2010). However, as the frequency of electric field oscillations increases beyond a few hundred hertz, sensitivity to stimulation and brain responses diminishes (Deans et al., 2007). On the one hand, this is readily attributable to the low-pass filtering characteristics of cell membranes (Ranck, 1975; Mclntyre and Grill, 1999; Bikson et al., 2004; Deans et al., 2007). Emerging neuromodulation techniques specifically using $\mathrm{kHz}$ frequency stimulation have been developed, in some cases with marked clinical efficacy. This includes transcranial alternating current stimulation (tACS) with sinusoidal kHz waveforms (Chaieb et al., 2011), transcranial random noise stimulation (tRNS; Terney et al., 2008; Antal and Paulus, 2013; Laczó et al., 2014), kHz spinal cord stimulation (SCS; Kapural et al., 2015; De Carolis et al., 2017), and, recently, kHz deep brain stimulation (DBS; Harmsen et al., 2019; Khadka et al., 2020). Approaches using interferential or intersectional short pulse stimulation (Grossman et al., 2017; Vöröslakos et al., 2018; Esmaeilpour et al., 2020) are a special case underpinned by an assumption of sensitivity to amplitude-modulated (AM) $\mathrm{kHz}$ field, but no responses to unmodulated $\mathrm{kHz}$ stimulation.

Across this proliferation of techniques and application of $\mathrm{kHz}$ neuromodulation, the cellular mechanisms of $\mathrm{kHz}$ electrical stimulation remain unclear (Dmochowski and Bikson, 2017; Pelot et al., 2017). While, at very high stimulation intensities, $\mathrm{kHz}$ stimulation may produce supraphysiological changes [e.g., conduction block (Zhang et al., 2006; Crosby et al., 2017), electroporation (Dowden et al., 2010)], for existing clinical applications these intensities are not expected at target tissue. Given that the response of neurons to $\mathrm{kHz}$ electrical stimulation is attenuated, the possibility of subthreshold stimulation of baseline neuronal activity (where ongoing neuronal activity is modulated; Bikson et al., 2013b) is considered alongside suprathreshold stimulation (de novo generation of action potentials/pacing).

Our goal was to systematically evaluate the sensitivity of hippocampal synaptic function and oscillatory network activity to kilohertz $(\mathrm{kHz})$ frequency extracellular electrical stimulation. For assessing the sub and supra-threshold effects of electric stimulation on brain excitability, the application of uniform electric fields across the rodent slice preparation is among the longest-standing and most

Author contributions: Z.E., M.J., and M.B. designed research; Z.E. and M.J. performed research; Z.E. analyzed data; Z.E., G.K., T.Z., R.E., B.H., and M.B. wrote the paper.

M.B. is supported by National Institutes of Health Grants R01NS101362, R01NS095123, R01NS112996, R01MH111896, and R01MH109289.

Correspondence should be addressed to Zeinab Esmaeilpour at znb. esmailpoor@gmail.com.

https://doi.org/10.1523/ENEURO.0368-20.2020

Copyright (C) 2020 Esmaeilpour et al.

This is an open-access article distributed under the terms of the Creative Commons Attribution 4.0 International license, which permits unrestricted use, distribution and reproduction in any medium provided that the original work is properly attributed. exhaustively studied animal models (Jefferys, 1981; Bikson et al., 2004; Jackson et al., 2016). fEPSPs, including pair-pulse responses, are sensitive to modulation by electric fields through changes in axonal excitability (Kabakov et al., 2012; Rahman et al., 2017), synaptic activity (Rahman et al., 2013), dendritic activity (Bikson et al., 2004; Kronberg et al., 2017), and somatic activity (Radman et al., 2009; Fröhlich and McCormick, 2010), while generally providing a global index for excitatory and inhibitory synaptic efficacy (Jefferys, 1981), information processing (Gluckman et al., 1996; Radman et al., 2007; Lafon et al., 2017), and plasticity (Fritsch et al., 2010; Ranieri et al., 2012; Kronberg et al., 2017). Neuronal network oscillations, including those in the $\gamma$ frequency band, are highly sensitive to electric fields through wellcharacterized mechanisms of amplification (Deans et al., 2007; Fröhlich and McCormick, 2010; Reato et al., 2010).

Here, we use fEPSP and oscillations to test the effect of 1- and $10-\mathrm{kHz}$ electrical stimulation using sinusoidal symmetric and asymmetric pulse waveforms. We used direct current (DC) electrical stimulation as a within-slice control to confirm the sensitivity to low-frequency stimulation. Our data suggest the presence of diminished neuronal sensitivity in response to $\mathrm{kHz}$ stimulation consistent with the dramatic low-pass filtering property of the neuronal membrane. Oscillatory networks (e.g., $\gamma$ oscillation) are more sensitive to electrical stimulation but only to $1-\mathrm{kHz}$ stimulation at $\geq 60-\mathrm{V} / \mathrm{m}$ intensity. Thus, consistent with results using sub-kHz electric fields, the structure of ongoing network oscillations would determine maximal sensitivity and effects of stimulation (Reato et al., 2013). If the brain is sensitive to high-kHz frequencies (i.e., $10 \mathrm{kHz}$ ) or lower-amplitude stimulation, it may be via mechanisms yet to be identified in the brain slice preparation (e.g., peculiarly sensitive neuronal elements, non-neuronal elements such as neuroglia, vascular response, heating), effects peculiar to non-uniform fields, and/or effects with a gradual (e.g., hours) onset.

\section{Materials and Methods}

All animal experiments were conducted in accordance with guidelines and protocols approved by the Institutional Animal Care and Use Committee at The City Collage of New York (CUNY).

\section{Hippocampal slice preparation}

Hippocampal brain slices were prepared from male Wistar rats aged three to five weeks old, which were deeply anaesthetized with ketamine $\left(7.4 \mathrm{mg} \mathrm{kg}^{-1}\right)$ and $\mathrm{xy}-$ lazine $\left(0.7 \mathrm{mg} \mathrm{kg}^{-1}\right)$ applied intraperitoneally and killed by cervical dislocation. The brain was quickly removed and immersed in chilled $\left(2-6^{\circ} \mathrm{C}\right)$ dissecting solution containing the following: $110 \mathrm{~mm}$ choline chloride, $3.2 \mathrm{~mm} \mathrm{KCl}, 1.25$ $\mathrm{mm} \mathrm{NaH} \mathrm{PO}_{4}, 26 \mathrm{~mm} \mathrm{NaHCO}, 0.5 \mathrm{~mm} \mathrm{CaCl}, 7 \mathrm{~mm}$ $\mathrm{MgCl}_{2}, 2 \mathrm{~mm}$ sodium ascorbate, $3 \mathrm{~mm}$ sodium pyruvate, and $10 \mathrm{~mm}$ D-glucose. Transverse hippocampal slices (400 $\mu \mathrm{m}$ thick) were cut using a vibrating microtome (Campden Instruments) and transferred to a recovery chamber for $30 \mathrm{~min}$ at $34^{\circ} \mathrm{C}$ with a modified artificial CSF (ACSF) containing the following: $124 \mathrm{~mm} \mathrm{NaCl}, 3.2 \mathrm{~mm}$ 
$\mathrm{KCl}, 1.25 \mathrm{~mm} \mathrm{NaH}_{2} \mathrm{PO}_{4}, 26 \mathrm{~mm} \mathrm{NaHCO}$, $2.5 \mathrm{~mm} \mathrm{CaCl}_{2}$, $1.3 \mathrm{~mm} \mathrm{MgCl} 2$, $2 \mathrm{~mm}$ sodium ascorbate, $3 \mathrm{~mm}$ sodium pyruvate, and $25 \mathrm{~mm}$ D-glucose. Slices were then transferred to a holding chamber for at least $30 \mathrm{~min}$ (or until needed) at $30^{\circ} \mathrm{C}$ with ACSF containing the following: 124 $\mathrm{mm} \mathrm{NaCl}, 3.2 \mathrm{mM} \mathrm{KCl}, 1.25 \mathrm{~mm} \mathrm{NaH} \mathrm{PO}_{4}, 26 \mathrm{~mm}$ $\mathrm{NaHCO}_{3}, 2.5 \mathrm{~mm} \mathrm{CaCl}, 1.3 \mathrm{~mm} \mathrm{MgCl}$, and $25 \mathrm{~mm}$ D-glucose. For fEPSP experimental recordings, slices were then transferred to a fluid-gas interface recording chamber (Hass top model, Harvard Apparatus) perfused with warmed


periments, slices were transferred to a fluid-gas interface recording at $34^{\circ} \mathrm{C}$. All solutions were saturated with a gas mixture of $95 \% \mathrm{O}_{2}-5 \% \mathrm{CO}_{2}$. $\gamma$ Oscillations were induced by perfusing the slices with ACSF containing $20 \mu \mathrm{m}$ carbachol (carbamoylcholine chloride). All reagents were purchased from Sigma-Aldrich.

\section{fEPSP recording (acute and long term)}

Recordings started $30 \mathrm{~min}$ after transfer to the recording chamber. fEPSPs were evoked in the Schaffer collateral pathway using a platinum-iridium bipolar stimulating electrode placed in stratum radiatum of CA1 $\sim 300 \mu \mathrm{m}$ from stratum pyramidale. Recording electrodes made from glass micropipettes (aluminosilicate glass with 1.5$\mathrm{mm}$ outer diameter, 1.0-mm inner diameter) pulled by a Sutter Instruments P-97 and filled with ACSF (resistance 0.5-2 $\mathrm{M} \Omega$ ) were placed in stratum radiatum of CA1, $\sim 400 \mu \mathrm{m}$ from the stimulating electrode and within $100 \mu \mathrm{m}$ from stratum pyramidale (Fig. 1). fEPSPs were quantified by the average initial slope, taken during the first $0.5 \mathrm{~ms}$ after the onset of the fEPSP. Stimulus intensity was set to evoke fEPSPs with $35-50 \%$ of the maximum slope, which was determined at the onset of recording. For paired-pulse facilitation (PPF) experiments, two fEPSPs were evoked at a 50-ms interval (Korte et al., 1995; Lessmann and Heumann, 1998; Kronberg et al., 2017). PPF was quantified as the ratio of the second to the first fEPSP slope in each condition.

For acute experiments, fEPSPs were evoked every $30 \mathrm{~s}$, alternating between control and $\mathrm{kHz}$ (or Direct current stimulation (DCS)) conditions. Waveforms were applied for $1 \mathrm{~s}$ and fEPSPs were evoked midway (0.5 s, mid-field; MF) through the stimulation (Fig. 1). Where indicated, fEPSPs were also evoked $0.1 \mathrm{~ms}$ after the extracellular field was turned off (post-field; PF). For control conditions, fEPSPs were evoked alone (no $\mathrm{kHz}$ stimulation). Within a given slice, a single $\mathrm{kHz}$ waveform was tested at multiple intensities in a randomized order ranging from 1 to $80 \mathrm{~V} / \mathrm{m}(1,5,10,20,40,60$, and $80 \mathrm{~V} /$ m) with each intensity repeated 3-15 times per slice. fEPSP slopes during each $\mathrm{kHz}$ epoch were normalized to the average of the control fEPSP slopes immediately preceding and following it. Normalized fEPSP slopes were then averaged across the repeats for each intensity, producing one $n$ per slice per waveform.

For long-term experiments, fEPSPs were evoked every $30 \mathrm{~s}$ and fEPSP slope was monitored online. After at least $30 \mathrm{~min}$ of stable baseline fEPSP recordings, 1 and $10 \mathrm{kHz}$ waveforms were applied parallel to the somato-dendritic axis (radial) at $80 \mathrm{~V} / \mathrm{m}$ for $30 \mathrm{~min}$. fEPSPs were continuously evoked every $30 \mathrm{~s}$ throughout the $\mathrm{kHz}$ and for 60 min after $\mathrm{kHz}$ ended. To determine stability before stimulation, a least squares linear fit was applied to the baseline fEPSP slopes. The slope of the linear fit $(\mathrm{mV}$ $\mathrm{ms}^{-1} \mathrm{~min}^{-1}$ ) was required to be $<0.33 \%$ of the mean baseline fEPSP slopes (i.e., $<20 \%$ drift expected over $60 \mathrm{~min}$ ). For the control condition, the same stability criteria were used, but no stimulation was applied. To quantify long-term effects, fEPSP slopes were normalized to the mean of the $20 \mathrm{~min}$ immediately preceding high-frequency stimulation. Sampling frequency was reduced to $10 \mathrm{kHz}$ during long-term experiments in both 1- and 10$\mathrm{kHz}$ stimulation because of technical limitations. The responses were compared between sham and control condition in three different times (immediately, $30 \mathrm{~min}$, and $60 \mathrm{~min}$ after termination of stimulation).

\section{Data analysis}

All data are reported as the mean \pm SEM. Reported $n$ values represent the number of slices used in each condition. Statistical analysis was performed using unpaired, one sample $t$ test for positive and negative DC control stimulation, after checking for normality in each group (Lilliefors test for normality, $p>0.05$ in all cases) and oneway repeated measure ANOVA for different intensities used in $\mathrm{kHz}$ waveforms. Bonferroni correction was used for multiple comparison correction. All the analysis was performed in R (RStudio).

\section{Bayesian inference}

Difference across highest electric field intensity and baseline were analyzed using the Bayesian paired samples $t$ test as implemented in JASP v0.13.1.0 using default effect size prior (Cauchy 0.707; Keysers et al., 2020). Results are reported using two tailed Bayes factor $\mathrm{BF}_{+0}$ that represents $\mathrm{p}\left(\mathrm{H}_{+} \mid 80 \mathrm{v} / \mathrm{m} \neq\right.$ baseline $) / \mathrm{p}\left(\mathrm{H}_{0} \mid 80 \mathrm{v} / \mathrm{m}=\right.$ baseline). Effect size estimates are reported as median posterior Cohen's $\delta$ with $95 \%$ credibility interval $(\mathrm{Cl})$ using a two-tailed $\mathrm{H}_{1}$ in order not to bias estimates in the expected direction. Bayesian ANOVAs were conducted using JASP with default priors, and effects are reported as Bayes factor for the inclusion of a particular effect, calculated as the ratio between the likelihood of the data given the model with versus the next simpler model without that effect.

\section{Electrical filed stimulation}

$\mathrm{kHz}$ and DCS extracellular electric fields were applied to slices via two parallel $\mathrm{Ag}-\mathrm{AgCl}$ wires (1-mm diameter, $12-\mathrm{mm}$ length, $10 \mathrm{~mm}$ apart) placed in the recording chamber on opposite sides of the brain slice with the recording site approximately equidistant from each wire. Slices were oriented so that the resulting electric field was either parallel (radial stimulation) or perpendicular (tangential stimulation) to the somato-dendritic axis of CA1 pyramidal neurons (Fig. 1). In CA3 experiments, slices were oriented so that the resulting electric field was parallel to the main somato-dendritic axis of CA3a pyramidal 

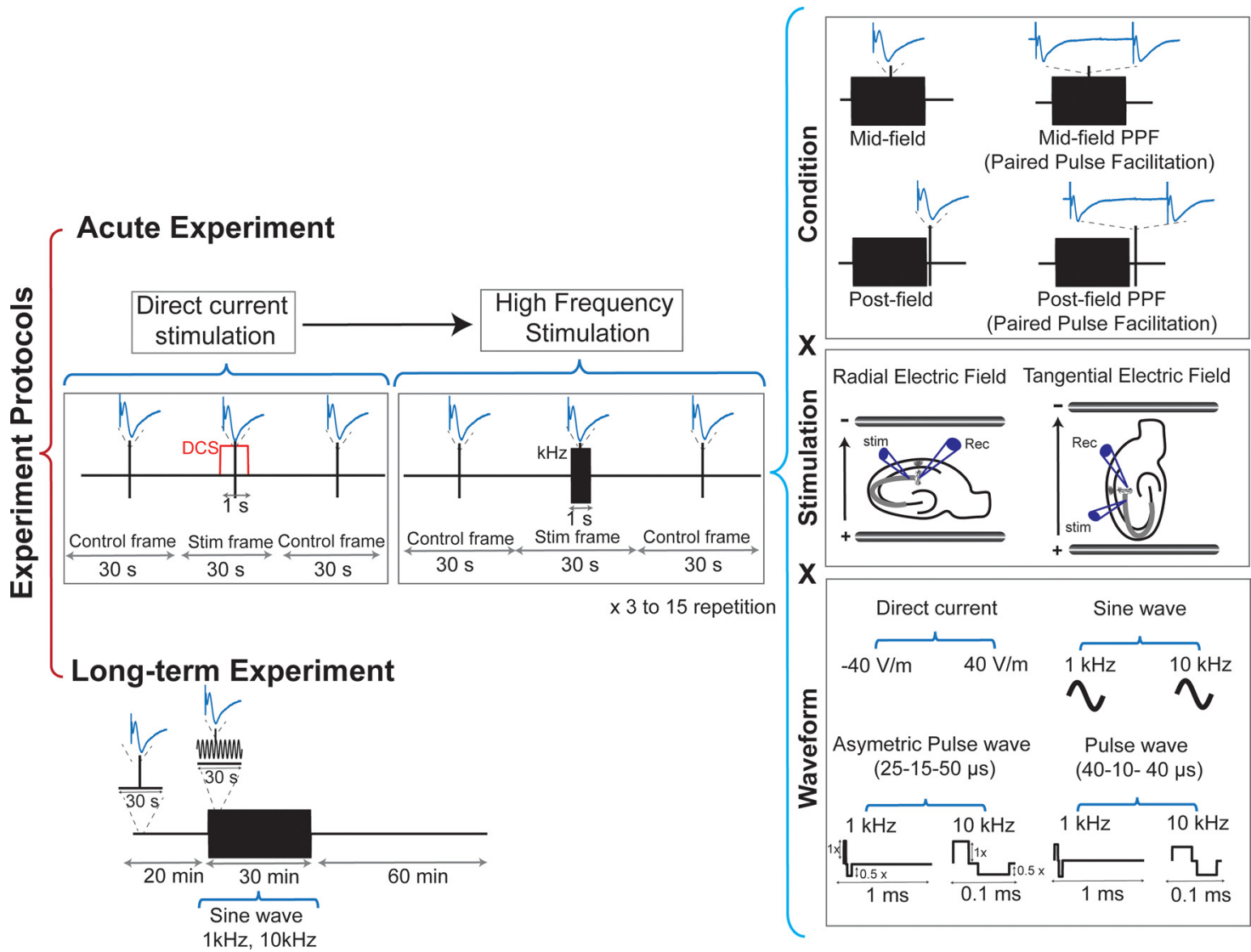

Figure 1. Experimental design of hippocampal slice recordings. Acute experiments: DC stimulation as within-slice control condition before high-frequency stimulation paradigm. fEPSP was evoked and recorded in four different conditions: MF, mid-filed PPF, PF, and PF PPF. Bipolar stimulation and glass recording electrodes depicted in CA1 stratum radiatum along with a pyramidal neuron and Schaffer collateral (gray). Stimulation: field wires were placed on opposite sides across the slice and connected to a current source. In radial configuration electric fields were applied parallel to the CA1 pyramidal somato-dendritic axis and in tangential configuration, electric fields were applied perpendicular to the CA1 pyramidal somato-dendritic axis. Waveform: DC and various electric field waveforms for $\mathrm{kHz}$ stimulation. The duration of each waveform component is given in $\mu \mathrm{s}$ for $1 \mathrm{kHz}$ and $10-\mathrm{kHz}$ stimulation. Alternating control and $\mathrm{kHz}$ (or DC) epochs were repeated every $30 \mathrm{~s}$. Raw data were low pass filtered to obtain fEPSPs for analysis. fEPSP obtained during kHz/DCS (MF) or $0.1 \mathrm{~ms}$ after kHz/DCS (PF) were normalized to the average of proceeding and following fEPSP. Long-term experiment: fEPSP was evoked every $30 \mathrm{~s}$. Stimulation was applied for 30 min after a 20 -min stable baseline. fEPSP recording was continued $1 \mathrm{~h}$ after the end of stimulation.

neurons (perpendicular to pyramidal cell layer; Fig. 1A.1). Field wires were connected to a custom high band-width voltage-controlled isolated current source. Before each recording, the applied current intensity was calibrated by measuring the electric field (voltage difference between two recording electrodes separated by $0.8 \mathrm{~mm}$ in the slice) in response to a $10-\mu \mathrm{A} D C$ test pulse. This characterized the linear relationship between electric field magnitude and applied current, which was then used to determine the current intensity required for a desired electric field. Data acquisition and stimulation waveforms were controlled by Power1401-625 kHz hardware and Signal software version 6.0 [Cambridge Electronic Design (CED)]. Voltage signals were amplified $(10 \times)$, analog low pass filtered $(20 \mathrm{kHz}$; Model 3000 differential amplifier, A-M Systems) and digitized $(200 \mathrm{kHz}$, Power1401$625 \mathrm{kHz}$ and Signal, CED). Before analyzing the fEPSP slope, all signals were digitally low pass filtered with Signal 6.0 (FIR filter, 2047 coefficients, 250-Hz transition gap, $1099-3 \mathrm{~dB}$ ) or MATLAB to remove stimulation artifact $(700-\mathrm{Hz}$ cutoff for $1-\mathrm{kHz}$ stimulation and $1-\mathrm{kHz}$ cutoff for $10-\mathrm{kHz}$ stimulation).

$\mathrm{kHz}$ was applied at 1 and $10 \mathrm{kHz}$ using the following $\mathrm{kHz}$ waveforms (leading polarity pulse width, interphase interval, opposite polarity pulse width): sinusoid, pulse (40-10-40 $\mu$ s for 1 and $10 \mathrm{kHz}$ ), and an asymmetric pulse waveform with the shorter duration pulse at $2 \times$ the amplitude of the longer duration pulse (25-15-50 $\mu$ s for $10 \mathrm{kHz}$; Fig. 1). Reported magnitude for the asymmetric pulse waveform is the electric field during the leading (shorter) pulse. For each slice, DCS at $40 \mathrm{~V} / \mathrm{m}$ was applied with alternating polarity before $\mathrm{kHz}$ waveforms as a basis for comparing effect sizes. Here, positive, radial + DCS refers to uniform DC electric fields that are parallel to the somato-dendritic axis of CA1 pyramidal neurons, with the positive terminal closer to the apical dendrites (as opposed to basal dendrites). Positive, tangential DCS refers to uniform DC electric fields that are parallel to Schaffer 
collaterals in CA1 with DCS current flow in the same direction as orthodromic action potential propagation (Fig. 1). Unless otherwise stated, the electric field reported throughout the manuscript is the peak electric field for each waveform.

\section{Extracellular recordings ( $\gamma$ oscillation)}

Recordings of extracellular field potentials in the pyramidal layer of CA3a and CA3c region of hippocampus were obtained using glass micropipettes (15 $\mathrm{M} \Omega$ pulled on a P-97, Sutter Instruments) field with ACSF. Data acquisition and electrical stimulation were controlled by Power1401$625 \mathrm{kHz}$ hardware and Signal software version 6.0 (CED). Voltage signals were amplified $(10 \times)$, analog low pass filtered $(20 \mathrm{kHz}$; Model 3000 differential amplifier, A-M Systems) and digitized $(20 \mathrm{kHz}$, Power1401-625 kHz and Signal, CED). To reduce noise and stimulation artifacts, the voltage recordings were always performed relative to an isopotential electrode placed in bath (Fig. 5A.1). Field recordings overcome potential limitations of intracellular recording during $\mathrm{kHz}$ field such as current collection by the capacitivewalled microelectrode leading to artifactual intracellular stimulation (FallahRad et al., 2019) or possible amplifier distortion (Lesperance et al., 2018).

\section{Power analysis and statistics}

Signals were recorded in frames of $5 \mathrm{~s}(1.5 \mathrm{~s}$ before and $1.5 \mathrm{~s}$ after stimulation) and stimulation was applied for $2 \mathrm{~s}$. Stimulation artifacts were minimized by subtracting the voltage in an iso-potential refence electrode from the recording electrode in the slice (Fig. 5). Spectrograms were computed (200-ms hamming window, $90 \%$ overlap) on individual 5-s frames and averaged over 100 frames for each stimulation condition (i.e., frequency, waveform and amplitude). Normalized power was measured as a power ratio normalized by prestimulation power in the frequency band of the endogenous oscillation. Mean $\gamma$ power was calculated in the center frequency of oscillation $(5-\mathrm{Hz}$ window). To quantify the slope of poststimulation, a line was fitted within a 300-ms window immediately after stimulation turned off using the "polyfit" function in MATLAB 2016b (MathWorks Inc). All the results are reported as mean $\pm \mathrm{SEM} ; n=$ number of slices. For statistical analysis paired $t$ test was used to compare poststimulation and prestimulation in each electric field intensity and significance level $(p)$ was corrected using Bonferroni for multiple (e.g., for four comparisons made in each experiment, $p<0.0125$ was considered significant). All the analysis was performed in $\mathrm{R}$ (RStudio).

\section{Results}

\section{Effect of kHz stimulation on hippocampal field potentials in CA1}

Field EPSPs (fEPSPs) measured at dendrites reflect the aggregate postsynaptic current entering to a population of neurons, which is a measure of synaptic input. fEPSPs are sensitive to low-frequency electric fields (Bikson et al., 2004; Lafon et al., 2017). Using rat hippocampal slice preparation, we tested the acute and long-term effects of uniform unmodulated $\mathrm{kHz}$ electric fields on synaptic efficacy with electric field direction in parallel or perpendicular to primary somato-dendritic axis (Bikson et al., 2004). The effects of DC electric field were also assessed as within-slice positive controls. fEPSPs were evoked in CA1 region of rat hippocampus by activating the Schaffer collateral pathway. Unless otherwise stated, changes in fEPSP slope from electric field application were calculated as a ratio of slope during electric field application versus control (i.e., no stimulation). PPF which is a measure of short-term synaptic plasticity was used in our recording and was calculated as the ratio of the second fEPSP slope to the first (50-ms interpulse interval) in each condition. Unless otherwise stated, results are reported as mean \pm SEM and stimulation were applied for $1 \mathrm{~s}$ in all acute experiments and $30 \mathrm{~min}$ in long-term experiments.

When electric fields were applied in the radial direction (electric field parallel to the somato-dendritic axis of CA1 pyramidal neurons), sinusoidal stimulation with $1 \mathrm{kHz}$ did not produce significant effects $\left(F_{(6,75)}=0.5835, \mathrm{~ns}\right)$ in any of intensities tested $(1,5,10,20,40,60,80 \mathrm{~V} / \mathrm{m})$. However, DC stimulation significantly modulated fEPSP slope [-DC $(1.06 \pm 0.014, N=24, p<0.01)+D C(0.932 \pm$ $0.0127, N=24, p<0.01)]$. Neither DC nor $1-\mathrm{kHz}$ sinusoidal stimulation affected PPF. Increasing stimulation frequency from 1 to $10 \mathrm{kHz}$ (fEPSP, $10 \mathrm{kHz}: F_{(6,160)}=0.86$, ns; PPF, $10 \mathrm{kHz}: F_{(6,55)}=2.8$, ns), or changing recording time from during stimulation to immediately after the field was turned off (fEPSP, $1 \mathrm{kHz} F_{(6,66)}=1.21$, ns; PPF $F_{(6,66)}$ $=0.88$, ns; fEPSP, $10 \mathrm{kHz} F_{(7,175)}=2.2$, ns, $\operatorname{PPF} F_{(7,47)}=$ $1.316, \mathrm{~ns})$ did not modulate fEPSP over the range of electric field intensities tested (Fig. 2B,C).

Symmetric and asymmetric charge-balanced waveforms are ubiquitous in implanted stimulators including DBS and SCS. Stimulation with radially-directed symmetric pulse waveforms at $1-$ and $10-\mathrm{kHz}$ electric fields did not modulate fEPSP $\left(1 \mathrm{kHz}, F_{(6,73)}=0.788\right.$, ns; $10 \mathrm{kHz}$, $\left.F_{(6,50)}=1.03, \mathrm{~ns}\right)$ or PPF $\left(1 \mathrm{kHz}, F_{(6,72)}=1.30, \mathrm{~ns} ; 10 \mathrm{kHz}\right.$, $F_{(6,61)}=0.68$, ns; Fig. $\left.2 E, F\right)$. Radially directed electric fields with asymmetric pulse waveform also did not modulate fEPSP or PPF regardless of frequency (fEPSP: $1 \mathrm{kHz}$, $F_{(6,15)}=0.63$, ns; $10 \mathrm{kHz}, F_{(6,84)}=1.022$, ns; PPF: $1 \mathrm{kHz}$, $F_{(2,9)}=0.72$, ns; $10 \mathrm{kHz}, F_{(2,32)}=0.86$, ns; Fig. 2G,H).

When electric field was applied in tangential direction (i.e., perpendicular to somato-dendritic axis of CA1 pyramidal neurons), sinusoidal waveform ( $1 \mathrm{kHz}$ : fEPSP, $F_{(6,105)}=0.231$, ns, PPF, $F_{(5,90)}=0.58$, ns; $10 \mathrm{kHz}$ : fEPSP $F_{(7,83)}=1.52$, ns; Fig. $3 A, D)$, symmetric $\left(1 \mathrm{kHz}\right.$ : fEPSP, $F_{(6,96)}=0.08$, ns, PPF, $\left.F_{(6,96)}=0.52, \mathrm{~ns}\right)$, and asymmetric waveforms (10 kHz: fEPSP, $F_{(6,36)}=1.71$, ns, PPF, $F_{(6,41)}=1.30$, ns), at $1 \mathrm{kHz}$ or $10 \mathrm{kHz}$, did not modulate fEPSPs.

Whereas all the prior results used brief application of electric fields, we further tested whether stimulation for a longer period (i.e., $30 \mathrm{~min}$ ) can induce lasting effects on fEPSP under the hypothesis that small effects could be amplified with longer stimulation duration. Stable baseline fEPSP was recorded every $30 \mathrm{~s}$ for over $20 \mathrm{~min}$ before stimulation and $60 \mathrm{~min}$ after stimulation. Electrical stimulation was done using sinusoidal $1-$ and $10-\mathrm{kHz}$ stimulation with $80-\mathrm{V} / \mathrm{m}$ electric field intensity (Fig. 4) and effect 
A Sine $1 \mathrm{kHz}$ WM
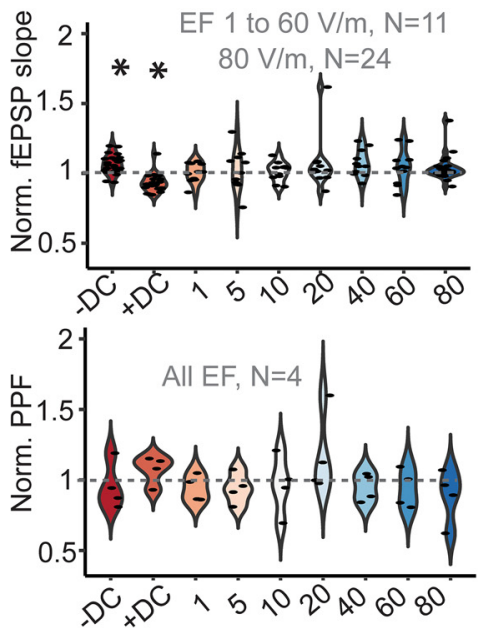

D Sine Wave-Post field, $10 \mathrm{kHz}$
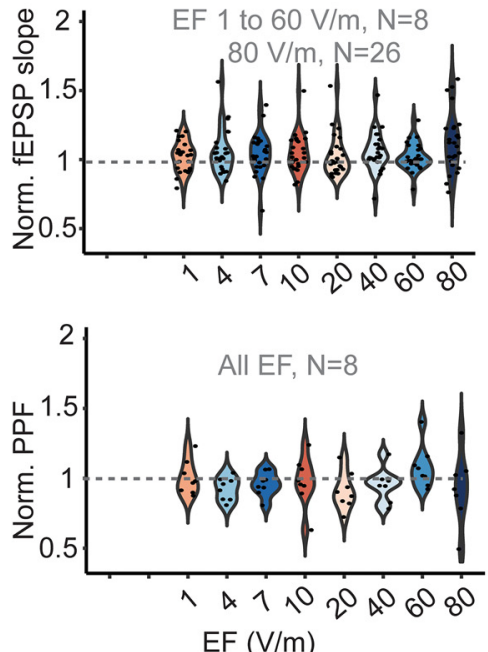

G Asymetric pulse Wave, $1 \mathrm{kHz} \sqcap$
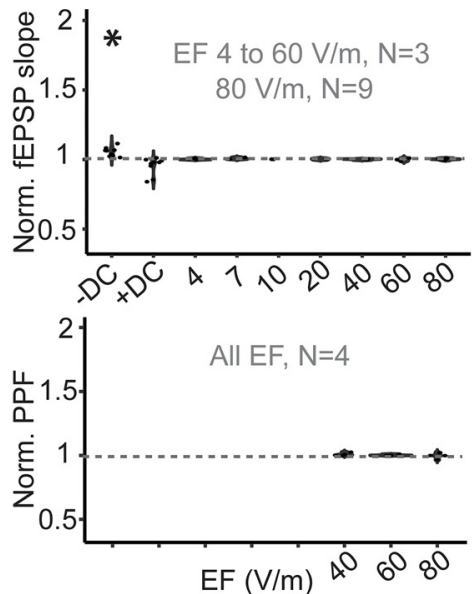

B Sine $10 \mathrm{kHz}$ WW
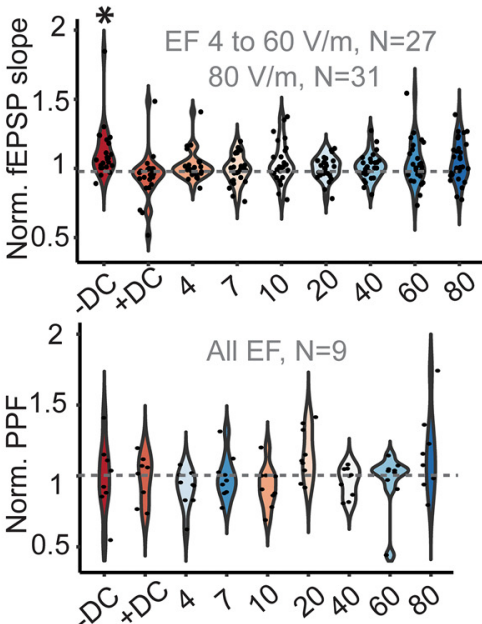

E Symmetric Pulse, $1 \mathrm{kHz}$
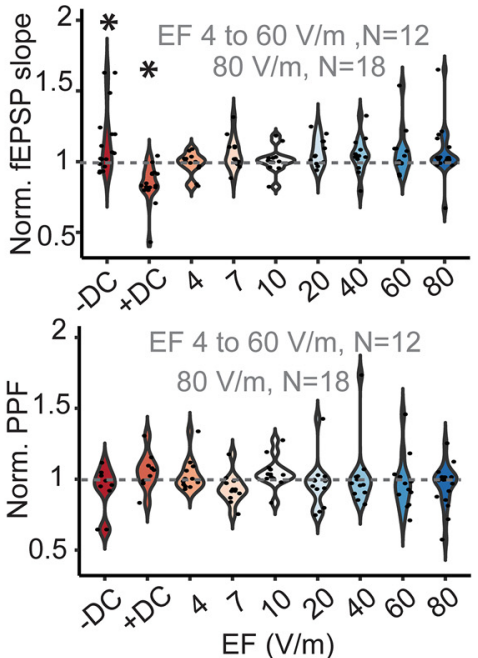

H Asymetric pulse Wave, $10 \mathrm{kHz} \sqcap$
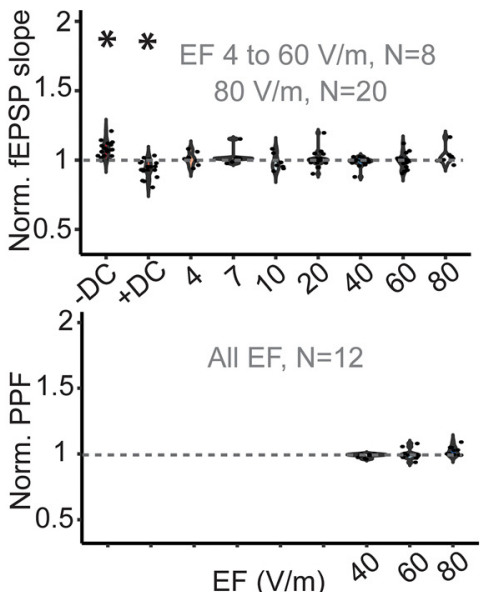

C Sine Wave-Post field, $1 \mathrm{kHz}$ uW/
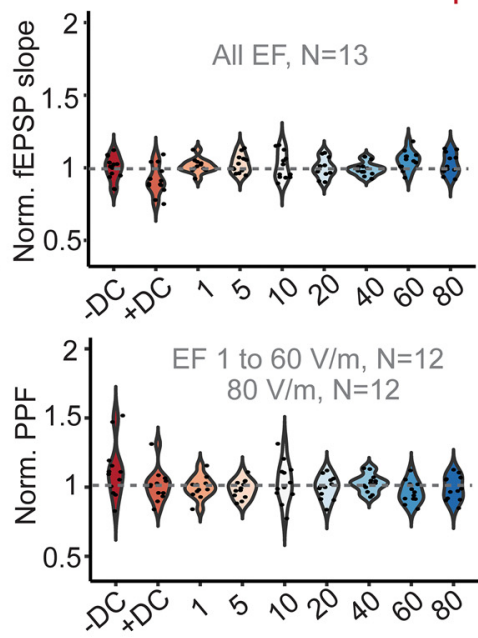

F Symmetric Pulse, $10 \mathrm{kHz}$ ـ
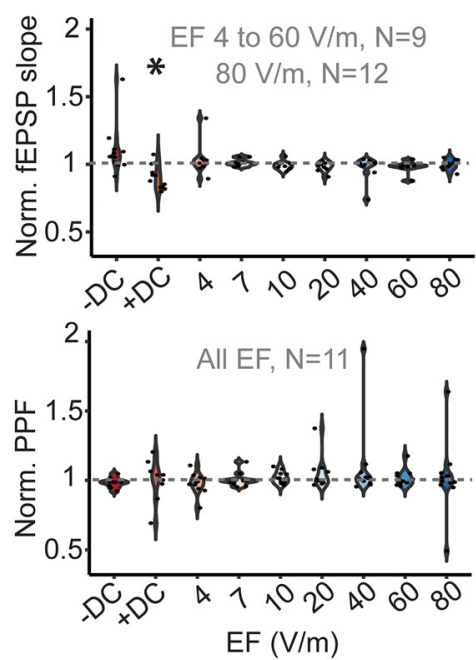
continued

and negative $40 \mathrm{~V} / \mathrm{m} \mathrm{DC}$ and $1-\mathrm{kHz}$ asymmetric pulse waveform stimulation. $\boldsymbol{H}$, Normalized slope of fEPSP and PPF during positive and negative $40 \mathrm{~V} / \mathrm{m} \mathrm{DC}$ and $10-\mathrm{kHz}$ asymmetric pulse waveform stimulation. Black circles indicate each data point. Recording frame was $30 \mathrm{~s}$ long in all the acute experiments. Stimulation was applied for $1 \mathrm{~s}$ in the middle of the recording frame $(14.5-15.5 \mathrm{~s})$. Each data point represents average of 3-15 repetition. $N$, the number of hippocampal slices in each intensity; EF, electric field; ${ }^{*} p<0.05$.

on fEPSP was analyzed for condition (i.e., sham, stimulation) and time (i.e., immediately, 30 and 60 min after termination of stimulation). A repeated measure ANOVA revealed no significant effects for stimulation condition $\left(1 \mathrm{kHz}: F_{(1,27)}=0.113\right.$, $\left.p=0.739 ; 10 \mathrm{kHz}: F_{(1,23)}=0.09, p=0.767\right)$, time $(1 \mathrm{kHz}:$ $\left.F_{(2,54)}=0.024, p=0.97 ; 10 \mathrm{kHz}: F_{(2,46)}=1.01, p=0.375\right)$, and no interactions ( $1 \mathrm{kHz}: F_{(2,54)}=1.01, p=0.37 ; 10 \mathrm{kHz}: F_{(2,46)}=$ $1.92, p=0.158)$.

\section{Bayesian analysis for supporting null hypothesis}

Since these negative results may support either evidence of absence (provide support for null hypothesis) or absence of evidence because of lack of statistical power, we performed Bayes factor hypothesis testing for fEPSP evoked during $80 \mathrm{~V} / \mathrm{m}$ stimulation applied in radial direction (parallel to somato-dendritic axis of pyramidal neurons) for 1 - and $10-\mathrm{kHz}$ sinusoidal, symmetric, and asymmetric waveforms. Moderate evidence was found for the absence of effect using $80 \mathrm{~V} / \mathrm{m}, 10-\mathrm{kHz}$ sinusoidal waveform, meaning that the observed data were $\sim 3 x$ more likely to be under the null hypothesis than the alternative $\left(\mathrm{BF}_{+0}=0.34\right.$ with median posterior $\delta=0.187$, $95 \% \mathrm{Cl}=[-0.177,0.560])$, and anecdotal evidence for absence of effect in $1-\mathrm{kHz}$ sinusoidal stimulation, meaning that the observed data were $1.67 \times$ more likely to be under the null hypothesis than the alternative $\left(\mathrm{BF}_{+0}=0.63\right.$ with median posterior $\delta=-0.334,95 \% \mathrm{Cl}=[-0.924,0.210])$.

Using Bayes factor in symmetric pulse waveforms showed that data observed in $10 \mathrm{kHz}$ is $\sim 3 \times$ more likely to be under the null hypothesis; providing moderate evidence for null $\left(\mathrm{BF}_{+0}=0.33\right.$ with median posterior $\delta=-0.122,95 \% \mathrm{Cl}=[-0.665,0.402])$ whereas observed data in $1 \mathrm{kHz}$ the data provided anecdotal evidence for
A Sine $1 \mathrm{kHz}$ WM
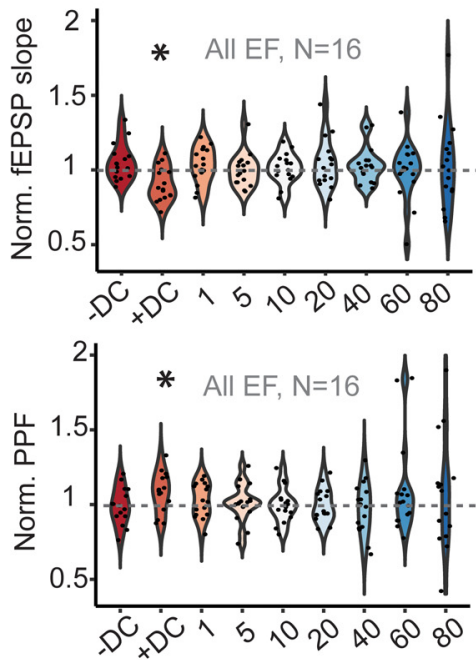

D Sine $10 \mathrm{kHz} \mathrm{Mm}$

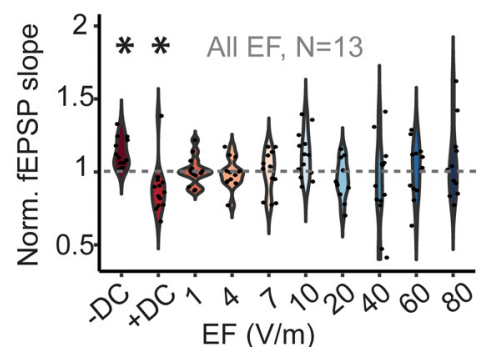

B Symmetric Pulse $1 \mathrm{kHz}$
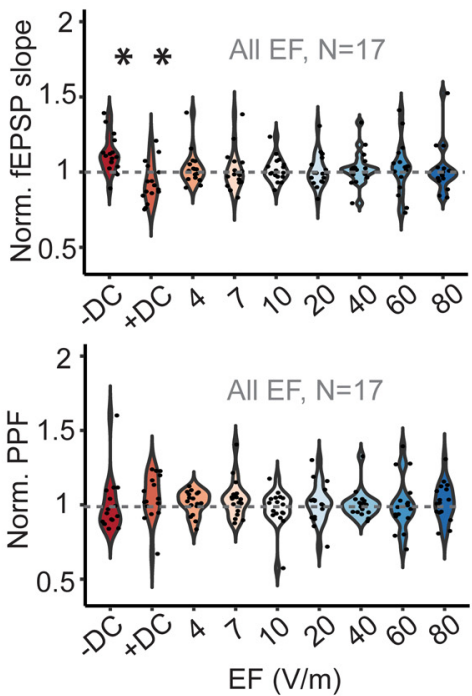

\section{Asymetric pulse $10 \mathrm{kHz} \sqcup$}
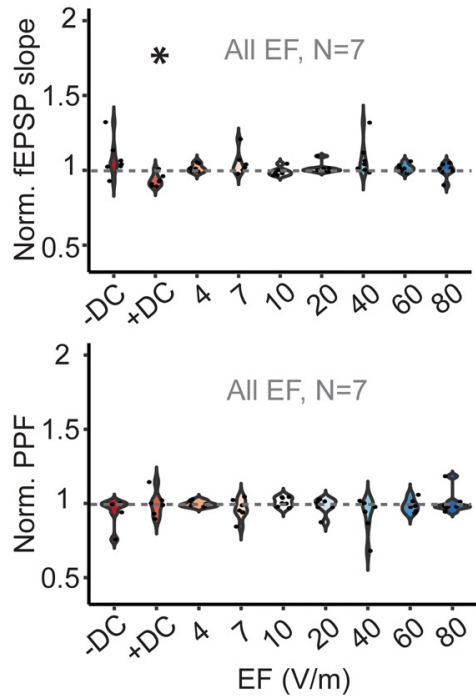

Figure 3. Acute effect of DC and high-frequency stimulation in tangential direction. A, Normalized slope of fEPSP and PPF during positive and negative $40 \mathrm{~V} / \mathrm{m} \mathrm{DC}$ and $1-\mathrm{kHz}$ sinusoidal stimulation. $\boldsymbol{B}$, Normalized slope of fEPSP and PPF during positive and negative $40 \mathrm{~V} / \mathrm{m}$ DC and 1-kHz symmetric pulse waveform. $C$, Normalized slope of fEPSP and PPF during positive and negative $40 \mathrm{~V} / \mathrm{m}$ DC and $10-\mathrm{kHz}$ asymmetric pulse waveform. $\boldsymbol{D}$, Normalized slope of fEPSP during positive and negative $40 \mathrm{~V} / \mathrm{m}$ DC and $10-\mathrm{kHz}$ asymmetric sine waveform. Colored circles indicate different data point. $N$, the number of hippocampal slices; EF, electric field; ${ }^{*} p<0.05$. 

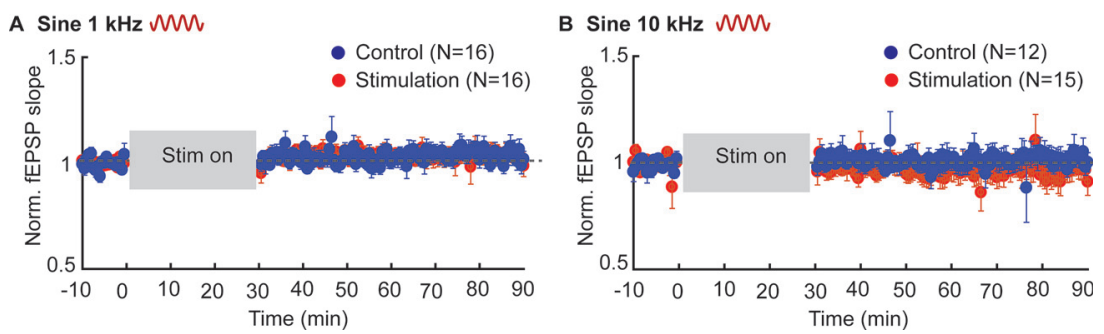

Figure 4. Long-term effect of $\mathrm{kHz}$ stimulation on synaptic efficacy. $\boldsymbol{A}$, Normalized fEPSP slope in response to 30 -min stimulation (between 0 and 30) 1-kHz sine waveform, $80 \mathrm{~V} / \mathrm{m}$ in radial direction after at least 20-min stable baseline. Follow-up recording continued for $60 \mathrm{~min}$ after stimulation. $\boldsymbol{B}$, Normalized fEPSP slope in response to $30 \mathrm{~min} 10-\mathrm{kHz}$ sine waveform, $80 \mathrm{~V} / \mathrm{m}$ in radial direction. Error bars indicates SEM. N, number of slices. Blue (control), red (stimulation).

null hypothesis: data were $1.33 \times$ more likely to be under the null hypothesis $\left(\mathrm{BF}_{+0}=0.75\right.$ with median posterior $\delta=0.369,95 \% \mathrm{Cl}=[-0.162,0.943])$. The data observed in during asymmetric pulse stimulation provided anecdotal evidence for both 1 - and $10-\mathrm{kHz}$ stimulation, meaning the observed data were $2.13 \times$ and $1.23 \times$ more likely to be under the null hypothesis, respectively $\left(1 \mathrm{kHz}: \mathrm{BF}_{+0}=0.47\right.$ with median posterior $\delta=-0.081$, $95 \% \mathrm{Cl}=[-1.004,0.789], 10 \mathrm{kHz}: \mathrm{BF}_{+0}=0.81$ with median posterior $\delta=-0.42,95 \% \mathrm{Cl}=[-0.216,1.143])$.

Bayesian repeated measure ANOVA revealed strong evidence $(1 \mathrm{kHz}$ : $B F=0.1 ; 10 \mathrm{kHz}$ : $B F=0.3)$ in support of the null hypothesis regarding effect of time (effect on EPSP immediate, $30 \mathrm{~min}$, or $60 \mathrm{~min}$ after stimulation) and moderate evidence $(1 \mathrm{kHz}$ : $B F=0.4,10 \mathrm{kHz}$ : $\mathrm{BF}=0.3)$ in support of the null hypothesis regarding effect of stimulation condition (i.e., sham vs stimulation on). Regarding interactions, Bayesian analysis revealed moderate and anecdotal evidence in support of the null hypothesis for 1 and $10 \mathrm{kHz}$, respectively $(1 \mathrm{kHz}$ : $B F=0.35,10 \mathrm{kHz}$ : $\mathrm{BF}=0.8)$.

\section{Effect of kHz stimulation on hippocampal $\gamma$ oscillations}

Uniform unmodulated $1-$ and $10-\mathrm{kHz}$ electric fields were applied across hippocampal slices exhibiting $\gamma$ oscillations under carbachol perfusion (Fig. 5A.1). Oscillations were typically stable over $\sim 3 \mathrm{~h}$, and experiments started after verifying stabilization of $\gamma$ oscillation power. We evaluated the sensitivity of $\gamma$ network activity to stimulation with $\mathrm{kHz}$ electric fields. Each stimulation was $2 \mathrm{~s}$ long and signals were recorded in frames of $5 \mathrm{~s}$ [acute effect, $5 \mathrm{~s}$ frame length (1.5 s pre, $2 \mathrm{~s}$ stim, 1.5 post), 80-100 frames per slice]. $\gamma$ Oscillation was recorded from both CA3a and $\mathrm{CA} 3 \mathrm{c}$ region of hippocampus. There was no significant difference in baseline $\gamma$ power between the two recording locations (CA3a, $N=14$; CA3c, $N=12$, ns; Fig. 5A.2).

Consistent with previous reports (Reato et al., 2010; Esmaeilpour et al., 2020), low kHz stimulation generated transient effect at the onset of stimulation as well as a sustained effect in CA3a region (Fig. 5B.1). This muted sustained effect is presumably reflecting homeostatic network regulation to bring the network back toward equilibrium (e.g., baseline oscillatory level). Moreover, stimulation produced a poststimulation suppression of oscillation (Figure
$5 B .1$, C.1), which is a marker of network rebound from homoeostatic adaptation (Reato et al., 2010). $\gamma$ Oscillation recorded from $\mathrm{CA3c}$ region was not modulated during stimulation (Fig. 5B.2), highlighting the importance of electric field direction relative to somato-dendritic axis of pyramidal neurons for somatic polarization (Radman et al., 2009).

Because of technical concerns of reliably removing stimulation artifact during $10-\mathrm{kHz}$ sinusoidal stimulation and symmetric pulse waveforms, oscillation data were analyzed comparing only the prestimulation and poststimulation time windows (Fig. 5C,D). We defined slope of average $\gamma$ power (see Materials and Methods) measured in 300-ms window immediately after termination of stimulation as a metric to quantify poststimulation suppression (Fig. 6).

Significant poststimulation suppression was detected using 1-kHz sinusoidal waveform with field intensities $\geq 60 \mathrm{~V} / \mathrm{m}$ in CA3a region ( $\gamma$ power slop: $60 \mathrm{~V} / \mathrm{m}$, post: $0.62 \pm 0.010$, pre: $8.5 \times 10^{-4} \pm 0.11, N=15, p<0.001 ; 80$ $\mathrm{V} / \mathrm{m}$; post: $0.83 \pm 0.09$, pre: $0.15 \pm 0.074, N=14, p<0.001$; Fig. 6A.1); however, in CA3c region, no change was detected in slope of $\gamma$ power immediately after stimulation (Fig. 6A.2). Similarly, symmetric pulse $1-\mathrm{kHz}$ stimulation using intensities $\geq 60 \mathrm{~V} / \mathrm{m}$ induced significant rebound after stimulation ( $\gamma$ power slope: $60 \mathrm{~V} / \mathrm{m}$, post: $0.58 \pm 0.06$, pre: $-0.15 \pm 0.23, N=7, p<0.01 ; 80 \mathrm{~V} / \mathrm{m}$, post: $0.77 \pm 0.11$, pre: $0.13 \pm 0.64, N=7, p<0.01$; Fig. $6 A .3)$. Increasing stimulation frequency from 1 to $10 \mathrm{kHz}$ abolished the effect. No effect was observed in 10-kHz symmetric pulse and sinusoidal stimulation using poststimulation suppressions as an index even when testing still higher electric field strength (i.e., 100, 120, and 150 V/m; Fig. 6B).

\section{Discussion}

There is a long-standing interest in explaining neuronal responses to $\mathrm{kHz}$ range electrical stimulation (Katz, 1939; Ward, 2009) with many results still inconclusive or without satisfactory theoretical treatment. Various forms of $\mathrm{kHz}$ neuromodulation techniques have shown promise in managing chronic pain (Al-Kaisy et al., 2015; Thomson et al., 2018) improving motor function in Parkinson's disease (Harmsen et al., 2019) and modulating excitability of human motor cortex (Terney et al., 2008; Chaieb et al., 2011; Antal and Paulus, 2013). Variations of $\mathrm{kHz}$ stimulation (electrode position, pulsed/sinusoidal waveforms) has been characterized in a broad range of applications 
A.1) In vitro

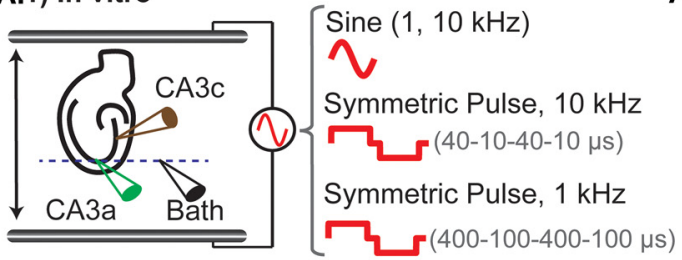

B.1) CA3a, Sine $1 \mathrm{kHz}$

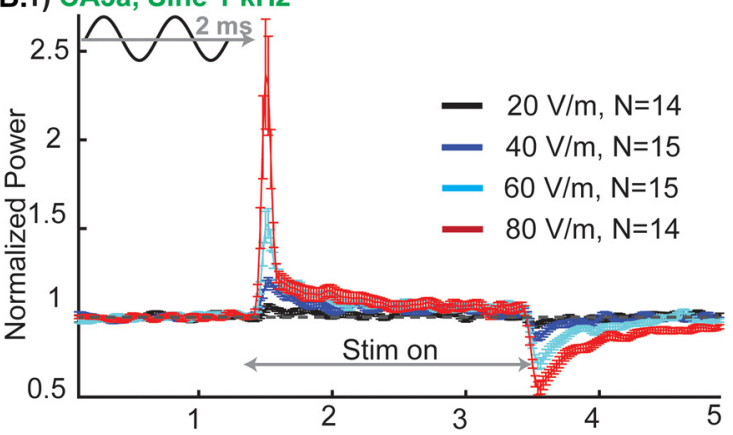

C.1) CA3a, Sine $10 \mathrm{kHz}$

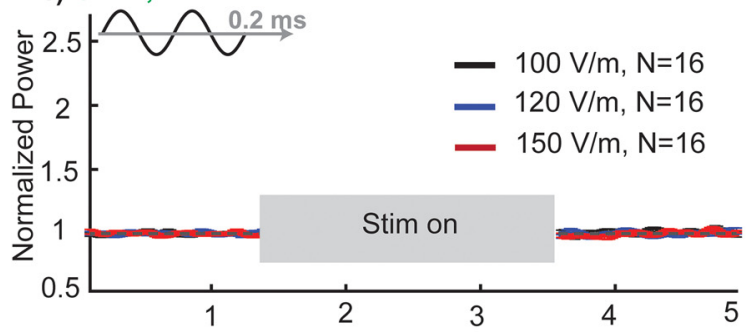

D.1) CA3a, Symmetirc Pulse $1 \mathrm{kHz}$

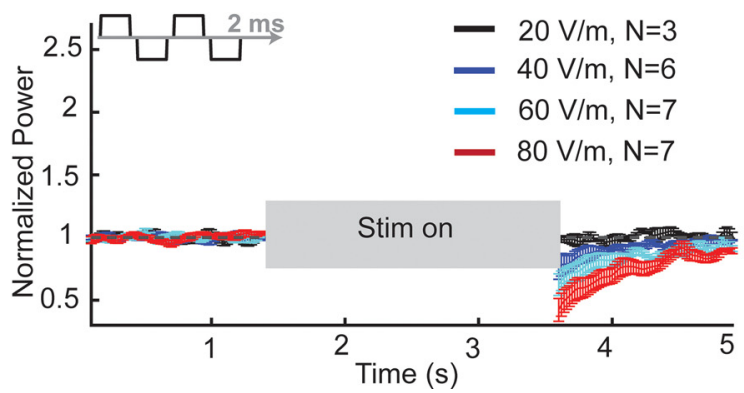

A.2) Baseline oscillation

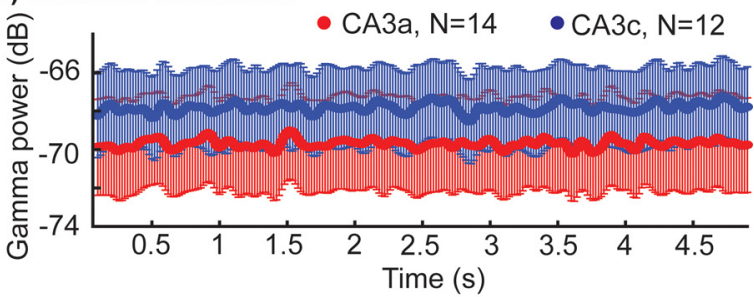

B.2) CA3c, Sine $1 \mathrm{kHz}$

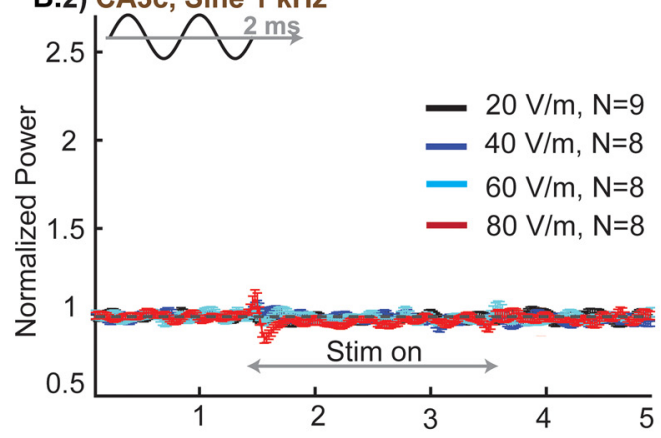

C.2) CA3c, Sine $10 \mathrm{kHz}$

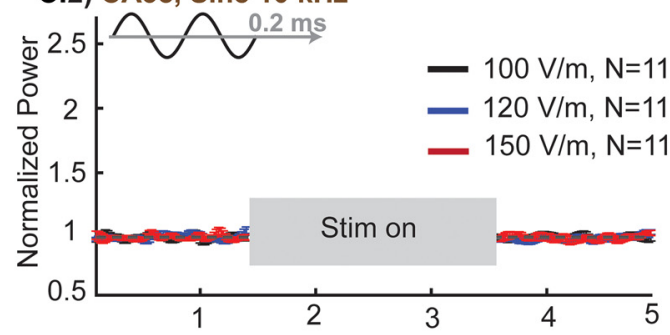

D.2) CA3a, Symmetric Pulse $10 \mathrm{kHz}$

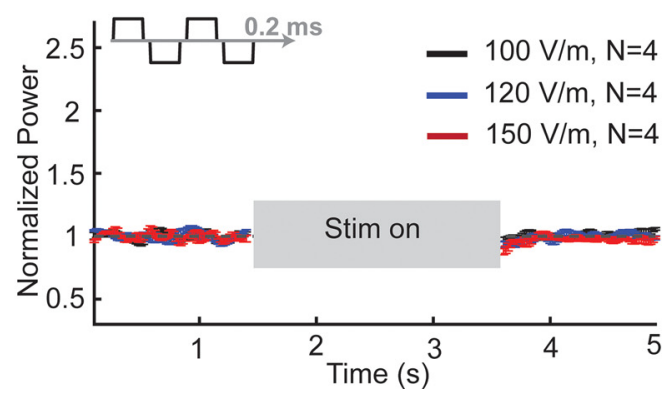

Figure 5. Sensitivity of hippocampal $\gamma$ oscillations during application of 1- and 10-kHz sinusoidal and square waveform stimulation. $\boldsymbol{A}$, Rat in vitro model of $\gamma$ oscillation. $\boldsymbol{A . 1}$, experimental setup: spatially uniform electric field was applied across hippocampal slices in an interface chamber. Recording of $\gamma$ oscillation from CA3a and CA3c relative to bath electrode to minimize stimulation noise. $\boldsymbol{A}$.2, Mean ( \pm SEM) of baseline $\gamma$ power (in dB) for CA3a and CA3c across slices. $\boldsymbol{B}$, Mean ( \pm SEM) of normalized $\gamma$ power across slices for $2 \mathrm{~s}$ of stimulation (between 1.5 and $3.5 \mathrm{~s}$ ) using 1-kHz sinusoidal waveform with different field intensities recorded from CA3a (B.1) and CA3c (B.2). C, Mean ( \pm SEM) of normalized $\gamma$ power across slices for $2 \mathrm{~s}$ of stimulation (between 1.5 and $3.5 \mathrm{~s}$ ) using 10-kHz sinusoidal waveform with different field intensities recorded from CA3a (C.1) and CA3c (C.2). $\boldsymbol{D}$, Mean ( \pm SEM) of normalized $\gamma$ power across slices for $2 \mathrm{~s}$ of stimulation (between 1.5 and $3.5 \mathrm{~s}$ ) using 1-kHz symmetric pulse waveform with different field intensities (D.1) and 10-kHz symmetric pulse waveform with different field intensities (D.2) recorded form CA3a region of rat hippocampus. $N$, number of slices.

including physiotherapy (Ward, 2009; Medeiros et al., 2017), ceasing abnormal neuronal activity (Kilgore and Bhadra, 2014; Lempka et al., 2015; Pelot and Grill, 2020) or generating spontaneous or asynchronous firing (Rubinstein et al., 1999; Litvak et al., 2003; Crosby et al., 2017). In contrast, it is a fundamental property of cells that the parallel leak conductance and capacitance of outer membrane forms an equivalent of a filter that attenuates neuronal responses to inputs with high-frequency components. This intrinsic low pass filtering property of neuronal membrane explains various electrophysiological finding at the cellular and neuronal network level on limited sensitivity to $\mathrm{kHz}$ electric fields (Deans et al., 2007; Reato et al., 2010), although once polarized, ions channel have some 

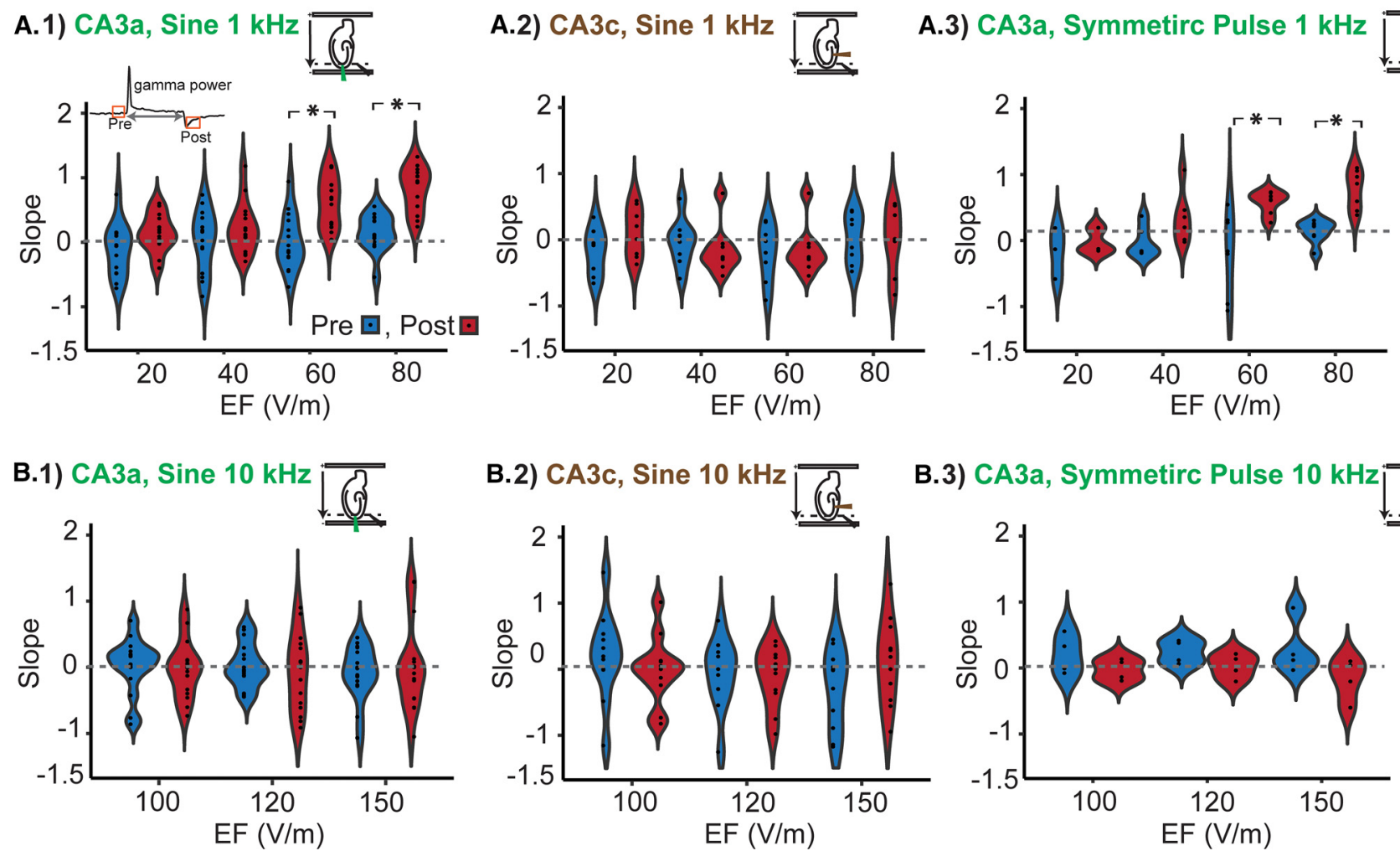

Figure 6. Post stimulation suppression of average $\gamma$ oscillation power. $\boldsymbol{A}$, Slope of mean $\gamma$ oscillation power (illustrated in Fig. 5) measured from 300-ms window immediately before and after $2 \mathrm{~s}$ of stimulation using 1-kHz sine waveform recorded from CA3a (A.1) and CA3c (A.2) and symmetric pulse waveform electrical stimulation recorded form CA3a region (A.3). B, Slope of $\gamma$ oscillation immediately before and after $10-\mathrm{kHz}$ stimulation recorded from CA3a (B.1) and CA3c (B.2) using sinusoidal and symmetric pulse waveform recorded from CA3c region (B.3). Red, poststimulation $\gamma$ slope. Blue, prestimulation $\gamma$ slope. ${ }^{*} p<0.05$.

kinetics with sub-ms time constants (Zhang et al., 2006; Zhao et al., 2014). At the same time, some application using $\mathrm{AM} \mathrm{kHz}$ stimulations are based on the assumption neurons are insensitive to the unmodulated $\mathrm{kHz}$ component (Goats, 1990; Ward, 2009; Grossman et al., 2017). We therefore set out to clarify the sensitivity of the brain to unmodulated, uniform, $1-$ or $10-\mathrm{kHz}$ sinusoidal (e.g., single frequency band) fields between 1 and $150 \mathrm{~V} / \mathrm{m}$.

The acute brain slice model has been extensively used as a model system to screen for effects of a broad range of stimulation waveform and intensities, including subthreshold fields (Bikson et al., 2004; Rahman et al., 2013, 2017; Jackson et al., 2016) and is generally among the most characterized experimental system in neuroscience (Ranieri et al., 2012). Consistent with screening for a broad range of possible effects, single and paired fEPSPs are sensitive to changes either in presynaptic or postsynaptic excitability. Oscillations are similarly highly sensitive to changes in excitatory and inhibitory cellular function through mechanism of amplification specific to network's architecture and level of activity (Reato et al., 2010, 2013; Jackson et al., 2016). Furthermore, field measures are insensitive to intracellular artifacts specific to $\mathrm{kHz}$ fields (Lesperance et al., 2018; FallahRad et al., 2019). A change in fEPSP or oscillations in response to
$\mathrm{kHz}$ electric fields are thus robust and broad indicators of changes in brain function, which, if positive, can then be followed by more specific testing to identify cellular targets.

We systematically evaluated responses to a range of waveforms (sinusoidal, symmetric, asymmetric pulses), intensities, 1- and 10-kHz frequencies, electric field direction (radial, tangential), stimulation duration (30 s typical, $30 \mathrm{~min}$ ), and during and PF effects. While impractical to test all combinations, our overall experimental strategy was intended to identify responses. We focused (number of slices) on $80 \mathrm{~V} / \mathrm{m}$ but tested a range of intensities in case responses are not monotonic. Given established sensitivity to DC fields of slice prep neurons (Bikson et al., 2004; Jackson et al., 2016), we conducted within-slice positive controls for general sensitivity to electric fields. By any measure, fEPSPs were not modulated by $\mathrm{kHz}$ waveform tested, regardless of intensity (up to $80 \mathrm{~V} / \mathrm{m}$ ), waveform, direction, or timing; 1 -but not 10-kHz electric field modulated ongoing network oscillations. The intensity required for $1-$ $\mathrm{kHz}$ electric fields to modulate $\gamma$ oscillation was substantially higher than for low-frequency (e.g., $\sim 100 \mathrm{~Hz}$ ) fields (Esmaeilpour et al., 2020). This overall lack of sensitivity is consistent with prior $\mathrm{kHz}$-stimulation mechanistic studies (Couto and Grill, 2016; Lempka et al., 
2015; Negahbani et al., 2018; Esmaeilpour et al., 2020) and the established low-pass filtering characteristics of neuronal membranes to electrical stimulation (Deans et al., 2007; Reato et al., 2013).

Our results are limited by several factors. It is never possible to exclude $\beta$ errors, though our use of a high SNR experimental system, with multiple slices and numerous repetitions per condition per slice, as well as within slice positive DC controls, together suggest such undetected effects would be variable or small in any case. Alternative mechanisms of electric fields such as ion concentration changes (Bikson et al., 2001; Shapiro et al., 2020; Wang et al., 2020), fiber block (Zhang et al., 2006; Zhao et al., 2014; Patel and Butera, 2015; Shapiro et al., 2020) and transverse axonal polarization (Wang et al., 2018) are suggested for $\mathrm{kHz}$ stimulation at very high intensities. However these very high intensities are not expected in existing clinical applications, such as SCS, with targeted tissue some $\mathrm{mm}$ away from the electrode (Lempka et al., 2015; Idlett et al., 2019). As emphasized throughout this article, these results are limited by any biophysical features absent from our experimental model system. Effective $\mathrm{kHz}$ stimulation with intensities comparable to these clinical applications would require a transduction mechanism with an especially fast time constant that is absent in acute rodent brain slice.

Following the quasi-uniform assumption (Bikson et al., 2013a, 2015; Khadka et al., 2019), we applied uniform fields, leaving open the possibility that geometrysensitive effects were missed (Idlett et al., 2019). Our results are limited to the intensities and specific waveforms tested, though a range of pulse-shapes were considered. We cannot consider possible mechanisms not captured by the hippocampal brain slice, such as a highly sensitive subtype of neurons (Rubinstein et al., 1999; Litvak et al., 2003; Lee et al., 2020), vascular responses (Cancel et al., 2018), or temperature (Zannou et al., 2019a,b); the latter in fact increases with $\mathrm{kHz}$ frequency.

\section{References}

Al-Kaisy A, Palmisani S, Smith T, Harris S, Pang D (2015) The use of 10-kilohertz spinal cord stimulation in a cohort of patients with chronic neuropathic limb pain refractory to medical management. Neuromodulation 18:18-23.

Antal A, Paulus W (2013) Transcranial alternating current stimulation (tACS). Front Hum Neurosci 7:317.

Bikson M, Lian J, Hahn PJ, Stacey WC, Sciortino C, Durand DM (2001) Suppression of epileptiform activity by high frequency sinusoidal fields in rat hippocampal slices. J Physiol 531:181191.

Bikson M, Inoue M, Akiyama H, Deans JK, Fox JE, Miyakawa H, Jefferys JG (2004) Effects of uniform extracellular DC electric fields on excitability in rat hippocampal slices in vitro. J Physiol 557:175190.

Bikson M, Dmochowski J, Rahman A (2013a) The "quasi-uniform" assumption in animal and computational models of non-invasive electrical stimulation. Brain Stimul 6:704-705.

Bikson M, Name A, Rahman A (2013b) Origins of specificity during tDCS: anatomical, activity-selective, and input-bias mechanisms. Front Hum Neurosci 7:688.
Bikson M, Truong DQ, Mourdoukoutas AP, Aboseria M, Khadka N, Adair D, Rahman A (2015) Modeling sequence and quasi-uniform assumption in computational neurostimulation. Prog Brain Res 222:1-23.

De Carolis G, Paroli M, Tollapi L, Doust MW, Burgher AH, Yu C, Yang T, Morgan DM, Amirdelfan K, Kapural L, Sitzman BT, Bundschu R, Vallejo R, Benyamin RM, Yearwood TL, Gliner BE, Powell AA, Bradley K (2017) Paresthesia-independence: an assessment of technical factors related to $10 \mathrm{kHz}$ paresthesia-free spinal cord stimulation. Pain Physician 20:331-341.

Cancel LM, Arias K, Bikson M, Tarbell JM (2018) Direct current stimulation of endothelial monolayers induces a transient and reversible increase in transport due to the electroosmotic effect. Sci Rep 8:1-13.

Chaieb L, Antal A, Paulus W (2011) Transcranial alternating current stimulation in the low $\mathrm{kHz}$ range increases motor cortex excitability. Restor Neurol Neurosci 29:167-175.

Couto J, Grill WM (2016) Kilohertz frequency deep brain stimulation is ineffective at regularizing the firing of model thalamic neurons. Front Comput Neurosci 10:22.

Crosby ND, Janik JJ, Grill WM (2017) Modulation of activity and conduction in single dorsal column axons by kilohertz-frequency spinal cord stimulation. J Neurophysiol 117:136-147.

Deans JK, Powell AD, Jefferys JG (2007) Sensitivity of coherent oscillations in rat hippocampus to $A C$ electric fields. J Physiol 583:555-565.

Dmochowski J, Bikson M (2017) Noninvasive neuromodulation goes deep. Cell 169:977-978.

Dowden BR, Wark HA, Normann RA (2010) Muscle-selective block using intrafascicular high-frequency alternating current. Muscle Nerve 42:339-347.

Esmaeilpour Z, Kronberg G, Reato D, Parra LC, Bikson M (2020) Temporal interference stimulation targets deep brain regions by modulating neural oscillations. Brain Stimul 14:55-65.

FallahRad M, Zannou AL, Khadka N, Prescott SA, Ratté S, Zhang T, Esteller R, Hershey B, Bikson M (2019) Electrophysiology equipment for reliable study of $\mathrm{kHz}$ electrical stimulation. J Physiol 597:2131-2137.

Fritsch B, Reis J, Martinowich K, Schambra HM, Ji Y, Cohen LG, Lu B (2010) Direct current stimulation promotes BDNF-dependent synaptic plasticity: potential implications for motor learning. Neuron 66:198-204.

Fröhlich F, McCormick DA (2010) Endogenous electric fields may guide neocortical network activity. Neuron 67:129-143.

Gluckman BJ, Netoff TI, Neel EJ, Ditto WL, Spano ML, Schiff SJ (1996) Stochastic resonance in a neuronal network from mammalian brain. Phys Rev Lett 77:4098-4101.

Goats G (1990) Interferential current therapy. Br J Sports Med 24:8792.

Grossman N, Bono D, Dedic N, Kodandaramaiah SB, Rudenko A, Suk HJ, Cassara AM, Neufeld E, Kuster N, Tsai LH, PascualLeone A, Boyden ES (2017) Noninvasive deep brain stimulation via temporally interfering electric fields. Cell 169:1029-1041. e16.

Harmsen IE, Lee DJ, Dallapiazza RF, De Vloo P, Chen R, Fasano A, Kalia SK, Hodaie M, Lozano AM (2019) Ultra-high-frequency deep brain stimulation at $10,000 \mathrm{~Hz}$ improves motor function. Mov Disord 34:146-148.

Idlett S, Halder M, Zhang T, Quevedo J, Brill N, Gu W, Moffitt M, Hochman S (2019) Assessment of axonal recruitment using model-guided preclinical spinal cord stimulation in the ex vivo adult mouse spinal cord. J Neurophysiol 122:1406-1420.

Jackson MP, Rahman A, Lafon B, Kronberg G, Ling D, Parra LC, Bikson M (2016) Animal models of transcranial direct current stimulation: methods and mechanisms. Clin Neurophysiol 127:34253454.

Jefferys J (1981) Influence of electric fields on the excitability of granule cells in guinea-pig hippocampal slices. J Physiol 319:143-152. 
Kabakov AY, Muller PA, Pascual-Leone A, Jensen FE, Rotenberg A (2012) Contribution of axonal orientation to pathway-dependent modulation of excitatory transmission by direct current stimulation in isolated rat hippocampus. J Neurophysiol 107:18811889.

Kapural L, Yu C, Doust MW, Gliner BE, Vallejo R, Sitzman BT, Amirdelfan K, Morgan DM, Brown LL, Yearwood TL, Bundschu R, Burton AW, Yang T, Benyamin R, Burgher AH (2015) Novel 10-kHz high-frequency therapy (HF10 therapy) is superior to traditional low-frequency spinal cord stimulation for the treatment of chronic back and leg pain: the SENZA-RCT randomized controlled trial. Anesthesiology 123:851-860.

Katz B (1939) Nerve excitation by high-frequency alternating current. J Physiol 96:202-224.

Keysers C, Gazzola V, Wagenmakers E-J (2020) Using Bayes factor hypothesis testing in neuroscience to establish evidence of absence. Nat Neurosci 23:788-799.

Khadka N, Truong DQ, Williams P, Martin JH, Bikson M (2019) The quasi-uniform assumption for spinal cord stimulation translational research. J Neurosci Methods 328:108446.

Khadka N, Harmsen IE, Lozano AM, Bikson M (2020) Bio-heat model of kilohertz-frequency deep brain stimulation increases brain tissue temperature. Neuromodulation 23:489-495.

Kilgore KL, Bhadra N (2014) Reversible nerve conduction block using kilohertz frequency alternating current. Neuromodulation 17:242-255.

Korte M, Carroll P, Wolf E, Brem G, Thoenen H, Bonhoeffer T (1995) Hippocampal long-term potentiation is impaired in mice lacking brain-derived neurotrophic factor. Proc Natl Acad Sci USA 92:8856-8860.

Kronberg G, Bridi M, Abel T, Bikson M, Parra LC (2017) Direct current stimulation modulates LTP and LTD: activity dependence and dendritic effects. Brain Stimul 10:51-58.

Laczó B, Antal A, Rothkegel H, Paulus W (2014) Increasing human leg motor cortex excitability by transcranial high frequency random noise stimulation. Restor Neurol Neurosci 32:403-410.

Lafon B, Rahman A, Bikson M, Parra LC (2017) Direct current stimulation alters neuronal input/output function. Brain Stimul 10:3645

Lee KY, Bae C, Lee D, Kagan Z, Bradley K, Chung JM, La JH (2020) Low-intensity, kilohertz frequency spinal cord stimulation differently affects excitatory and inhibitory neurons in the rodent superficial dorsal horn. Neuroscience 428:132-139.

Lempka SF, Mclntyre CC, Kilgore KL, Machado AG (2015) Computational analysis of kilohertz frequency spinal cord stimulation for chronic pain management. Anesthesiology 122:13621376.

Lesperance LS, Lankarany M, Zhang TC, Esteller R, Ratté S, Prescott SA (2018) Artifactual hyperpolarization during extracellular electrical stimulation: proposed mechanism of high-rate neuromodulation disproved. Brain Stimul 11:582-591.

Lessmann V, Heumann R (1998) Modulation of unitary glutamatergic synapses by neurotrophin-4/5 or brain-derived neurotrophic factor in hippocampal microcultures: presynaptic enhancement depends on pre-established paired-pulse facilitation. Neuroscience 86:399-413.

Litvak LM, Smith ZM, Delgutte B, Eddington DK (2003) Desynchronization of electrically evoked auditory-nerve activity by highfrequency pulse trains of long duration. J Acoust Soc Am 114:2066-2078.

McIntyre CC, Grill WM (1999) Excitation of central nervous system neurons by nonuniform electric fields. Biophys J 76:878888.

McIntyre CC, Grill WM, Sherman DL, Thakor NV (2004) Cellular effects of deep brain stimulation: model-based analysis of activation and inhibition. J Neurophysiol 91:1457-1469.

Medeiros FV, Bottaro M, Vieira A, Lucas TP, Modesto KA, Bo APL, Cipriano G, Jr, Babault N, Durigan JLQ (2017) Kilohertz and lowfrequency electrical stimulation with the same pulse duration have similar efficiency for inducing isometric knee extension torque and discomfort. Am J Phys Med Rehabil 96:388-394.

Negahbani E, Kasten FH, Herrmann CS, Fröhlich F (2018) Targeting alpha-band oscillations in a cortical model with amplitude-modulated high-frequency transcranial electric stimulation. Neuroimage 173:3-12.

Patel YA, Butera RJ (2015) Differential fiber-specific block of nerve conduction in mammalian peripheral nerves using kilohertz electrical stimulation. J Neurophysiol 113:3923-3929.

Pelot N, Grill W (2020) In vivo quantification of excitation and kilohertz frequency block of the rat vagus nerve. J Neural Eng 17: e026005.

Pelot NA, Behrend C, Grill W (2017) Modeling the response of small myelinated axons in a compound nerve to kilohertz frequency signals. J Neural Eng 14:046022.

Radman T, Su Y, An JH, Parra LC, Bikson M (2007) Spike timing amplifies the effect of electric fields on neurons: implications for endogenous field effects. J Neurosci 27:3030-3036.

Radman T, Ramos RL, Brumberg JC, Bikson M (2009) Role of cortical cell type and morphology in subthreshold and suprathreshold uniform electric field stimulation in vitro. Brain Stimul 2:215-228.e3.

Rahman A, Reato D, Arlotti M, Gasca F, Datta A, Parra LC, Bikson M (2013) Cellular effects of acute direct current stimulation: somatic and synaptic terminal effects. J Physiol 591:2563-2578.

Rahman A, Lafon B, Parra LC, Bikson M (2017) Direct current stimulation boosts synaptic gain and cooperativity in vitro. J Physiol 595:3535-3547.

Ranck JB (1975) Which elements are excited in electrical stimulation of mammalian central nervous system: a review. Brain Res 98:417-440.

Ranieri F, Podda MV, Riccardi E, Frisullo G, Dileone M, Profice P, Pilato F, Di Lazzaro V, Grassi C (2012) Modulation of LTP at rat hippocampal CA3-CA1 synapses by direct current stimulation. J Neurophysiol 107:1868-1880.

Reato D, Rahman A, Bikson M, Parra LC (2010) Low-intensity electrical stimulation affects network dynamics by modulating population rate and spike timing. J Neurosci 30:15067-15079.

Reato D, Rahman A, Bikson M, Parra LC (2013) Effects of weak transcranial alternating current stimulation on brain activity-a review of known mechanisms from animal studies. Front Hum Neurosci 7:687.

Rubinstein JT, Wilson BS, Finley CC, Abbas PJ (1999) Pseudospontaneous activity: stochastic independence of auditory nerve fibers with electrical stimulation. Hear Res 127:108-118.

Shapiro K, Guo W, Armann K, Pace N, Shen B, Wang J, Beckel J, de Groat W, Tai C (2020) Pudendal Nerve Block by Low-Frequency $(<1 \mathrm{kHz})$ Biphasic Electrical Stimulation. Neuromodulation. Advance online publication. Retrieved Aug 6 2020. doi: 10.1111/ner.13241.

Terney D, Chaieb L, Moliadze V, Antal A, Paulus W (2008) Increasing human brain excitability by transcranial high-frequency random noise stimulation. J Neurosci 28:14147-14155.

Thomson SJ, Tavakkolizadeh M, Love -Jones S, Patel NK, Gu JW, Bains A, Doan Q, Moffitt M (2018) Effects of rate on analgesia in kilohertz frequency spinal cord stimulation: results of the PROCO randomized controlled trial. Neuromodulation 21:67-76.

Vöröslakos $\mathrm{M}$, Takeuchi $\mathrm{Y}$, Brinyiczki $\mathrm{K}$, Zombori $\mathrm{T}$, Oliva $\mathrm{A}$, Fernández-Ruiz A, Kozák G, Kincses ZT, Iványi B, Buzsáki G, Berényi A (2018) Direct effects of transcranial electric stimulation on brain circuits in rats and humans. Nat Commun 9:483.

Wang B, Aberra AS, Grill WM, Peterchev AV (2018) Modified cable equation incorporating transverse polarization of neuronal membranes for accurate coupling of electric fields. J Neural Eng 15: e026003.

Wang Z, Pace N, Cai H, Shen B, Wang J, Roppolo JR, Groat WC, Tai C (2020) Poststimulation block of pudendal nerve conduction by highfrequency $(\mathrm{kHz})$ biphasic stimulation in cats. Neuromodulation 23:747753.

Ward AR (2009) Electrical stimulation using kilohertz-frequency alternating current. Phys Ther 89:181-190. 
Zannou AL, Khadka N, FallahRad M, Truong DQ, Kopell BH, Bikson M (2019a) Tissue Temperature Increases by a $10 \mathrm{kHz}$ Spinal Cord Stimulation System: Phantom and Bioheat Model. Neuromodulation. Advance online publication. Retrieved Jun 21 2019. doi: $10.1111 /$ ner.12980.

Zannou AL, Khadka N, Truong DQ, Zhang T, Esteller R, Hershey B, Bikson M (2019b) Temperature increases by kilohertz frequency spinal cord stimulation. Brain Stimul 12:62-72.
Zhang X, Roppolo JR, De Groat WC, Tai C (2006) Mechanism of nerve conduction block induced by high-frequency biphasic electrical currents. IEEE Trans Biomed Eng 53:2445-2454.

Zhao S, Yang G, Wang J, Roppolo JR, de Groat WC, Tai C (2014) Effect of non-symmetric waveform on conduction block induced by high-frequency $(\mathrm{kHz})$ biphasic stimulation in unmyelinated axon. J Comput Neurosci 37:377-386. 